Int. J. Dev. Biol. 49: 761-771 (2005)

doi: $10.1387 / \mathrm{ijdb} .052002 \mathrm{ps}$

\title{
Long-range signalling in plant reproductive development
}

\author{
PAULA SUÁREZ-LÓPEZ* \\ CSIC-IRTA Laboratory of Plant Molecular Genetics, Instituto de Biología Molecular de Barcelona, Spain
}

\begin{abstract}
Animals and plants produce regulatory signals at specific places of their bodies, in order to regulate developmental events which take place at a distance. Plants use this mechanism to adjust their development to the changing environment. Flowering and tuber formation are controlled by signals generated in the leaves that travel throughout the plant to reach their target tissues: the shoot apical meristem for flowering and the underground stolons for tuberization. Although the existence of these long-distance plant messengers was postulated almost seventy years ago, their chemical nature is still not clear. These leaf-derived signals are graft-transmissible and move through the plant vascular system. Presumably they are very similar or even identical for flowering and tuberization and common to most plant species. It is generally accepted that their composition is complex and includes positive and negative regulators. Many different substances, including classical plant hormones and metabolites have been postulated to be components of these mobile signals, but conclusive evidence of this is still lacking. Recent work has positioned these signals within the genetic network that regulates flowering time and suggests roles for specific genes in the generation, transport or response to the signalling molecules. Current knowledge of long-range signalling mechanisms in other physiological and developmental events, together with the finding of common regulators involved in flowering, tuberization and other processes like pathogen and wound responses, should help to establish the biochemical composition of these elusive messenger signals.
\end{abstract}

KEY WORDS: flowering, long-distance signal, photoperiodism, plant development, tuberization

\section{Introduction}

In multicellular organisms, communication among neighbouring cells and with distant parts of the growing body is crucial to achieve coordinated development and healthy growth. Vascular systems play an essential role both in delivering nutrients, oxygen, etc and in long-distance signalling for developmental processes. In animals, hormones synthesized at specific places travel through the vasculature to alter developmental patterns in target organs. Communication between distant organs is especially relevant in plants due to the fact that they cannot escape from adverse conditions. In order to survive and perpetuate, they have to adapt their growth and development to the changing environment. Non-cell-autonomous signalling is involved in many plant developmental processes, including shoot morphogenesis, shoot branching, root patterning, flowering and tuber formation (Jackson, 1999; Sessions et al., 2000; Nakajima et al., 2001; Jackson, 2002; Périlleux and Bernier, 2002; Ward and Leyser, 2004). This review focuses mainly on recent advances in longdistance signalling involved in the regulation of two plant reproductive processes, flowering - which is the main form of sexual reproduction - and tuberization - a mode of asexual or vegetative propagation. Current progresses in other physiological and developmental events that provide valuable information to understand long-range signalling in a broader context are also incorporated.

Evidence of long-distance signalling in plant development has come from several observations. The adult parts of a plant derive from the activity of two groups of stem cells, called meristems, situated at the tip of the root and at the apex of the shoot (Byrne et al., 2003). Development can be strongly influenced by environmental stimuli, which are often perceived by a plant part distant from the place, usually a meristem, undergoing the developmental response. Shoot development is influenced by stresses affect-

Abbreviations used in this paper: ABA, abscisic acid; AP1, APETALA1; bps1, bypass1 ; CO, CONSTANS; DCL1, DICER-LIKE1; dne, die neutralis; FT, FLOWERING LOCUS T; GA, gibberellin; gi, gigantea; GUS, $\beta$-glucuronidase; ID1, INDETERMINATE1;LD, long days; LFY, LEAFY;MAX, MOREAXILLARY BRANCHING; miRNA, microRNA; phyB, phytochrome B; ppd, photoperiod; RMS1, RAMOSUS 1; SD, short days; siRNA, short interfering RNA; sn, sterile nodes; SOC1, SUPPRESSOR OF OVEREXPRESSION OF CONSTANS; TFL1, TERMINAL FLOWER 1.

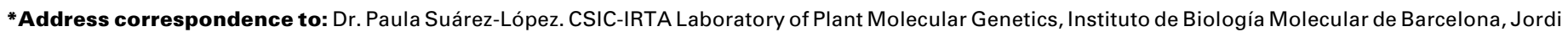
Girona, 18-26, 08034 Barcelona, Spain. Fax: +34-93-204-5904. e-mail: pslgml@cid.csic.es
} 
ing the roots, suggesting that roots send signals to the shoot (Jackson, 2002). Flowering and tuberization are regulated in many species by photoperiod, the relative duration of light and darkness during a day. Because the main site of photoperiod perception is the leaf, photoperiodic induction of flowering and tuberization requires transmission of signals from the leaves to either the shoot apical meristem, where flowering takes place, or the stolons, underground stems where tubers develop (Jackson, 1999; Périlleux and Bernier, 2002) (Fig. 1). Long-distance messengers regulate flowering in photoperiod-insensitive plants as well (Lang et al., 1977), indicating that internal signals can also trigger the production of mobile molecules. Grafting studies have provided proof for the existence of long-range signals in the regulation of flowering time, tuber induction, shoot branching and effects of roots on the shoot (Bernier et al., 1993; Jackson, 1999; Jackson, 2002; Ward and Leyser, 2004).

\section{Properties of the signal}

To understand long-distance signalling in flowering and tuberization it is convenient to distinguish three successive steps: 1) induction in the leaves, which determines the timing of the process; 2) commitment (also called evocation or determination) to flowering or tuberization at the shoot apical meristem or at the stolon tip, respectively; and 3) tuber initiation at the stolon tip or floral morphogenesis at the shoot apical meristem (Périlleux and Bernier, 2002). Thus, export of inducing signals from the leaves follows induction and precedes commitment. An alternative mode of commitment exists: leaves can become committed to continually produce the long-range signal (Hempel et al., 2000). Defoliation experiments indicate that a particular line of Impatiens balsamina is irreversibly committed to flowering because leaves exposed to inductive photoperiods produce a transmissible signal incessantly (Tooke et al., 1998). In other plants, like Chenopodium rubrum, Sinapis alba and Arabidopsis thaliana, leaf removal at different times indicates that commitment to flowering occurs at the shoot apex and, therefore, after the leaves have started to export the signal (King, 1972; Zeevaart, 1976; Corbesier et al., 1996). Loss of inductive conditions, however, can lead to partial or total reversion of the flowering process in soybean (Glycine max) (Washburn and Thomas, 2000), some lines of /. balsamina (Pouteau et al., 1997) and in other species (Zeevaart, 1976), as well as of tuberization in potato (Solanum tuberosum) (Ewing and Struik, 1992). This suggests that in these plants real commitment to flowering or tuberization does not take place, or occurs after floral or tuber development has already begun. In some species, therefore, these developmental processes are only completed if continuous inductive conditions are maintained. All these situations illustrate the wide variety of responses that can be found in nature.

Although it was initially proposed that flowering is triggered in inductive photoperiods by a single substance, which was named florigen, experimental results support that several transmissible components participate in the regulation of flowering onset (Bernier et al., 1993). Numerous grafting experiments have shown that leaves exposed to favourable or unfavourable photoperiods produce mobile substances capable of promoting or inhibiting flowering, respectively (Périlleux and Bernier, 2002). Evidence for positive and negative transmissible regulators of tuberization has also been obtained (Jackson, 1999). Furthermore, long-range signals are interchangeable between plants with different photoperiodic responses (Zeevaart, 1976). A good example is the acceleration of flowering in a day neutral tobacco cultivar under short day (SD) conditions when is grafted onto a tobacco cultivar that responds to SD and under long day (LD) conditions when it is grafted onto Nicotiana sylvestris, which responds to LD (Lang et al., 1977). Induction of tuberization by flowering signals has also been described. Tobacco scions kept under conditions inductive for flowering can promote tuberization when grafted onto potato stocks, whereas non-induced tobacco scions do not cause tuberization (Chailakhyan et al., 1981). An interpretation of these results is that long-distance signals for flowering and tuberization are identical or very similar for many plants, or even that the same signals are used by all higher plants, as has been pointed out by several authors (Zeevaart, 1976; Bernier et al., 1993). There is, however, a number of cases in which interspecific transmission of the signal could not be demonstrated (Zeevaart, 1976), suggesting that the floral stimulus might not be universal. On the other hand, lack of transmissibility between species could be explained by different amounts of signals formed in the leaves of different species, by different balances between positive and negative regulators, by different sensitivity of the shoot apex to the stimulus, or by rapid reversion to vegetative growth in some instances. As long as the chemical nature of the signals is not determined, it is impossible to establish whether these signals are universal or not.

\section{Generation and movement of graft-transmissible sig- nals}

Applying inductive photoperiods only to leaves can promote flowering (Hempel et al., 2000). This has led to the general assumption that mature leaves are the most effective site for photoperiod perception and generation of long-distance information substances (Périlleux and Bernier, 2002). In several species, however, fully expanded leaves are not required for sensing photoperiod. Defoliation experiments indicate that cotyledons of C. rubrum and I. balsamina seedlings produce a floral stimulus that is exported to the shoot apex under inductive SD (King, 1972; Pouteau et al., 1997). Given that Arabidopsis is committed to flower at about 7 inductive LD (Bradley et al., 1997), before any leaf has reached maturity, photoperiod must be perceived either by cotyledons or by very young leaves. In maize, the flowering signal is also produced by immature leaves (Colasanti et al., 1998). According to Chapman (Chapman, 1958), photoperiod is perceived by young rapidly expanding leaves in potato, since plants whose terminal leaf cluster is exposed to a particular photoperiod tuberize like whole plants exposed to the same conditions.

Long-distance signals that regulate the initiation of flowering and tuberization move through the phloem (Zeevaart, 1976; Jackson, 1999), which has two basic cell types, enucleate sieve elements and companion cells (Oparka and Turgeon, 1999). Any transported molecule has to enter the sieve elements (phloem loading), move with the phloem stream and then leave it (phloem unloading) (Ruiz-Medrano et al., 2001). It is clear that longdistance signalling can have regulatory mechanisms at many levels: synthesis of signals, transport to the vascular bundles, 
phloem loading, translocation in the phloem sap, phloem unloading, entry into the target tissues and sensitivity of the target cells to the signals.

In potato, the factors that induce tuberization are found throughout the entire plant (Gregory, 1956) and the signal can move both basipetally (from apex to base) and acropetally (from base to apex) (Kumar and Wareing, 1973) (Fig. 1). However, tuber formation always occurs at the physically lowest nodes of the plant, even if a stem cutting is planted in an inverted position (Kumar and Wareing, 1973), suggesting a strong effect of gravity either in the accumulation of the stimulus, or in the competence to respond to it.

For flowering, the stimulus has to be transported at least acropetally, since flowering occurs at the shoot apical meristem (Fig. 1). In several species, including tobacco, orchids and Arabidopsis, there is a gradient in the potential to flower, decreasing from the apical nodes (Zeevaart, 1976; Bowman, 1994). It is not known whether this gradient is caused by differential movement or accumulation of the floral stimulus, or different sensitivities of the axillary meristems to the mobile signals.

\section{Genes involved in generation, movement and percep- tion of long-distance signals}

The production of positive and negative components of the mobile signal, the balance between them, their transport to the shoot apex or the stolon tip and the sensitivity of these target tissues to the signals are probably controlled by genes that affect flowering or tuberization time. Despite the abundance of flowering-time genes identified and characterized in Arabidopsis (Mouradov et al., 2002; Boss et al., 2004), little is known about their role in the generation and movement of the long-distance signals. This is due, in part, to the lack of suitable grafting methods for this species until very recently (Turnbull et al., 2002) and to the use of Arabidopsis mainly for genetic and molecular rather than physiological studies. Other plant species offer experimental advantages that have allowed some progress in understanding the role of several genes in leaf-to-apex communication.

In maize, the INDETERMINATE1 (ID1) gene is required to promote the transition to reproductive growth, as id1 mutants flower later than wildtype plants (Colasanti et al., 1998). The analysis of an id1 mutant caused by a transposon insertion in this gene revealed that plants containing sectors in which the transposon had excised flowered earlier than fully mutant id1 plants, even though the revertant sectors did not affect the shoot apical meristem (Colasanti et al., 1998). This indicates that $I D 1$ acts in a non-cell-autonomous manner. Since this gene is expressed only in immature leaves (Colasanti et al., 1998), it must regulate the production or transport of a signal exported to the shoot apex to induce flowering.

Several genes are involved in the generation of a graft-transmissible floral inhibitor in pea and at least one in the production of a floral stimulus (Weller et al., 1997b). In this plant, the positive signal seems to be produced constitutively

(Beveridge and Murfet, 1996). Flowering is thought to occur when the ratio of stimulus to inhibitor exceeds a certain threshold (Weller et al., 1997b). This is achieved under LD because the photoreceptor phytochrome A reduces the production or transport of the inhibitor (Weller etal., 1997a). The gigas mutant of pea, affected in the production of the constitutive floral stimulus (Beveridge and Murfet, 1996), has a phenotype similar to that of Arabidopsis mutants classified in the autonomous (or constitutive) floral-promotion pathway (Koornneef et al., 1998), with late flowering and enhanced photoperiod and vernalization responses. In contrast, pea mutants affected in inhibitor production - the sterile nodes ( $s n$ ), die neutralis (dne) and photoperiod (ppd) mutants - flower early in a photoperiod-insensitive manner (Weller et al., 1997b). Despite being similar, the phenotype of the pea phytochrome $B$ (phy $B$ ) mutant is not graft-transmissible, suggesting that the level of a long-distance floral inhibitor is not altered (Weller et al., 2001). The isolation of the genes affected by the gigas, sn, dne and ppd pea mutations might be extremely valuable to identify mobile floral signals.

Work on potato has also provided information about genes involved in the production or movement of long-range signals. In this plant, tuberization is promoted in SD (Ewing and Struik, 1992) and PHYB represses tuber initiation under non-inductive LD conditions (Jackson et al., 1996). Potato plants that carry an antisense $P H Y B$ transgene tuberize in both photoperiods (Jackson et al., 1996). When antisense $P H Y B$ scions were grafted onto wild-type stocks, two different results were obtained: if all of the leaves in the stocks were removed, these formed tubers in LD, but when wild-type leaves were left, tuberization did not occur. Wildtype scions grafted onto antisense $P H Y B$ stocks inhibited tuber induction in LD (Jackson et al., 1998). These results are compatible with two hypotheses: either PHYB is required for the production of a graft-transmissible inhibitor of tuberization (Jackson et al., 1998) or PHYB is required for phloem loading of this inhibitor in the leaves. The tuberization phenotype of antisense PHYB potato plants is comparable to the flowering phenotype of pea phy $B$ mutants, with photoperiod insensitivity and earliness (Weller

Flowering

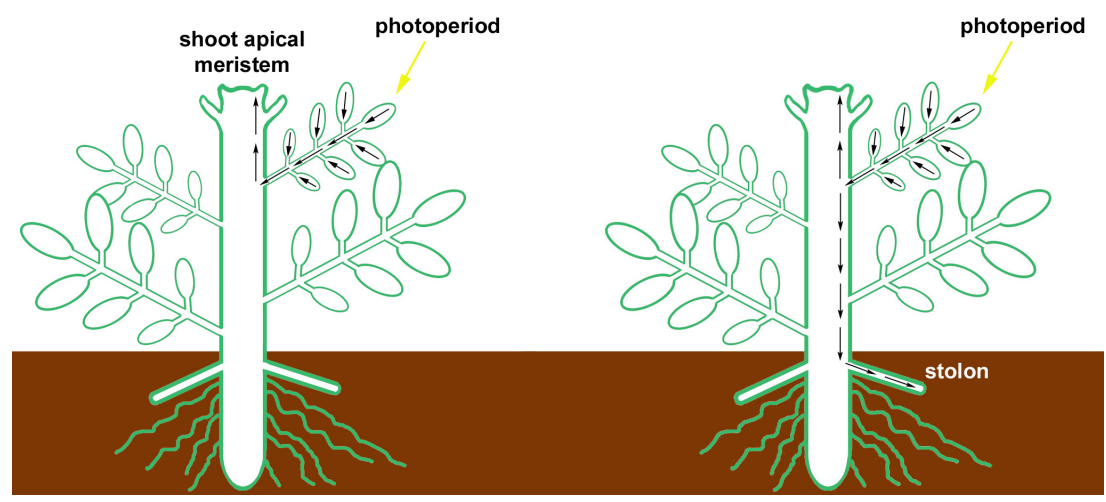

Fig. 1. Movement of long-range signals for flowering and tuberization. Photoperiod perception in the leaves gives rise to signals that are transmitted to the shoot apical meristem to induce flowering (left) or to underground stolons to induce tuberization (right). Black arrows indicate the direction of movement. In potato, tuber inducing signals are transmitted throughout the plant, but in normal growing conditions only the lowest nodes respond to them and develop tubers. 
et al., 2001). However, as mentioned above, a transmissible inhibitor is not affected in the pea phyB mutant (Weller et al., 2001).

CONSTANS (CO) is a central gene in the photoperiodic regulation of flowering in Arabidopsis (Searle and Coupland, 2004). CO encodes a nuclear zinc-finger protein required to promote flowering in inductive LD (Putterill et al., 1995; Robson et al., 2001). Expression of this Arabidopsis gene in potato delays tuberization under SD conditions, which promote tuber formation in wild-type plants (Martínez-García et al., 2002). Grafting experiments indicate that $\mathrm{CO}$ probably acts in the leaves, rather than in the stolons, to delay tuberization of CO-overexpressing potato plants (Martínez-García et al., 2002), suggesting that CO acts upstream of the graft-transmissible signal. Two research groups have recently shown that this is the case in Arabidopsis, placing the floral stimulus within the genetic network that controls flowering time (An et al., 2004; Ayre and Turgeon, 2004). Fusions of the CO promoter to the $\beta$-glucuronidase (GUS) reporter gene revealed GUS expression in the shoot apex, young leaves and the vascular tissue of the hypocotyl, cotyledons, leaves and roots (Takada and Goto, 2003; An et al., 2004). Expression of CO from several phloem-specific promoters was sufficient to complement the late-flowering phenotype of a co mutant in LD (An et al., 2004) and to accelerate flowering in a wild-type background in SD (Ayre and Turgeon, 2004). However, expression from meristem-specific promoters did not complement a co mutation (An et al., 2004), indicating that $\mathrm{CO}$ acts in the phloem to trigger flowering. Furthermore, when co mutant scions were grafted to wild-type stocks or to stocks expressing $\mathrm{CO}$ from a phloem promoter, the scions flowered earlier than co mutant controls (An et al., 2004; Ayre and Turgeon, 2004). Because the CO protein and mRNA do not seem to move from the phloem (An et al., 2004; Ayre and Turgeon, 2004), these results strongly support that $C O$ regulates the production or entry into the phloem of a long-distance flowering signal.

Within the complex genetic network that controls flowering time in Arabidopsis, the functions of numerous genes converge in the regulation of a few genes called floral pathway integrators, which include FLOWERING LOCUS T (FT) and SUPPRESSOR OFOVEREXPRESSION OF CONSTANS 1 (SOC1), also called AGAMOUS-LIKE 20 (Boss et al., 2004; Komeda, 2004). These two genes are direct targets of CO (Samach et al., 2000) and ultimately affect the expression or activity of a set of genes termed floral meristem identity genes (Komeda, 2004), which convert a vegetative meristem into a reproductive meristem that produces flowers (Pidkowich et al., 1999). $\angle E A F Y$ ( $\angle F Y)$ and APETALA1 $(A P 1)$, among others, are floral meristem identity genes. $\angle F Y$ is at least in part downstream of SOC1 (Lee et al., 2000), and AP1 has been proposed to act downstream of $F T$, which does not affect $\angle F Y$ expression (Ruiz-García et al., 1997; Nilsson et al., 1998). Another gene that acts at a similar level to $F T$ and that affects $A P 1$ but not $\angle F Y$ function is FWA (Ruiz-García et al., 1997). SOC1, FT and FWA might also affect other floral meristem identity genes (Ruiz-García et al., 1997; Lee et al., 2000). Since $\mathrm{CO}$ probably regulates the synthesis of the long-distance signal and the floral meristem identity genes act in the shoot apical meristem and therefore after the signal has reached this meristem, FT and SOC1 are good candidates to be involved in signal transport. Alternatively, the FT and SOC1 gene products might be part of this transmissible signal. FT expression is detected in the vasculature (Takada and Goto, 2003), it can be specifically induced by $C O$ in the phloem and it can promote flowering when directed by different tissue-specific promoters, including phloem and meristem promoters (An et al., 2004).

$\angle F Y$ probably has additional roles besides being a floral meristem identity gene. Many authors include $\angle F Y$ among the floral pathway integrators (Blázquez and Weigel, 2000; Mouradov et al., 2002; Boss et al., 2004; Komeda, 2004). LFY expression is upregulated upon floral induction (Blázquez et al., 1997; Hempel et al., 1997) and $\angle F Y$ in turn upregulates $A P 1$ expression (Liljegren et al., 1999). The increase in mRNA levels of these genes requires the activity of TERMINAL FLOWER 1 (TFL1) (Ratcliffe et al., 1998). TFL 1 shows sequence similarity to FT and animal phosphatidylethanolamine-binding proteins (Bradley et al., 1997; Kardailsky et al., 1999; Kobayashi et al., 1999). FT and TFL1 regulate flowering in an antagonistic manner, since $f t$ mutants flower later than the wild type (Koornneef et al., 1991) and tfl1 mutants are early flowering (Zagotta et al., 1992). Tfl1 mutants are committed to flower earlier than the wild type (Bradley et al., 1997), indicating that either the mobile signal is produced earlier, or is transported more rapidly, or the meristem is competent to respond to it earlier. All these alternative hypotheses associate TFL1 very closely with the generation, transport or response to the floral stimulus. Using the newly developed micrografting method in Arabidopsis (Turnbull et al., 2002), it should be relatively easy to test whether the phenotype of the $t f / 1$ mutant is graft-transmissible. It had been suggested previously that TFL1 might influence the response of the apex to mobile signals (Ratcliffe et al., 1998). Interestingly, a TFL1 homologue from pea, LATE FLOWERING (Foucher et al., 2003), controls the sensitivity of the apex to floral signals, is a repressor of flowering and its effects are not graft-transmissible (Weller et al., 1997b), giving support to the hypothesis of a similar role for TFL 1. The presence of the TFL1 mRNA below the shoot apical meristem (Bradley et al., 1997) is consistent with this hypothesis.

Very recent work shows that grafting late-flowering gigantea (gi) mutants to wild-type Arabidopsis stocks accelerates significantly flowering of gi (Turnbull and Justin, 2004), a result not surprising since $G /$ regulates $C O$ expression (Suárez-López et al., 2001). The flowering time of the $f t$ mutant, however, was only slightly reduced when grafted onto wild-type stocks (Turnbull and Justin, 2004). One interpretation of this result is that the wild-type stock can provide $F T$ function to the mutant scion, either because FT regulates the synthesis of a mobile signal or because the product of this gene is transported to the shoot apex. Nevertheless, since the acceleration of flowering in $\mathrm{ft}$ scions is small, another interpretation is that $F T$ is required for effective movement of the signal. Further investigation is necessary to establish the role of $F T$ in long-range signalling.

The use of the Arabidopsis micrografting assay (Turnbull etal., 2002) should allow examining whether other flowering-time genes play any role in the production or translocation of mobile signals.

\section{Putative mobile signals that regulate flowering and tuberization}

The existence of long-distance signals for flowering and tuberization has been known for several decades. Different mol- 
ecules have been proposed as components of the floral stimulus and inhibitor, but there is no conclusive proof so far that any of them is the flowering signal transmitted from the leaves to the shoot apical meristem. The main compounds postulated as grafttransmissible floral regulators are explained below and summarized in Table 1. A discussion of other molecules not included here can be found in several excellent reviews (Zeevaart, 1976; Bernier et al., 1993; Périlleux and Bernier, 2002).

\section{Hormones}

Several plant hormones are thought to regulate flowering by moving from the leaves to the shoot apex, based mainly on two approaches: the effect of mutations in genes affecting hormone synthesis or hormone signal transduction on flowering and the effect of exogenous applications of hormones or hormone inhibitors on flowering. Only for gibberellins (GAs) and cytokinins there is sufficient experimental evidence to be discussed in this review. For the possible role of other hormones, the reader is referred to previous reviews (Zeevaart, 1976; Bernier et al., 1993).

The effect of GAs on flowering time has been extensively reviewed recently (Périlleux and Bernier, 2002; King and Evans, 2003). Therefore, only a summary of the most significant data is presented here. It must be emphasized that different plant species respond in different ways to the external application of GAs, making difficult to draw general conclusions. GAs can be detected in phloem and xylem saps (Périlleux and Bernier, 2002), indicating that they can be transported. In Arabidopsis, GAs promote flowering, especially under SD conditions (Mouradov et al., 2002; Périlleux and Bernier, 2002; Boss et al., 2004). GAs activate the expression of $\angle F Y$ and SOC1 in Arabidopsis and of SaMADSA (the SOC1 homologue) in S. alba (Mouradov et al., 2002; Périlleux and Bernier, 2002). In several LD and SD species, GAs do not induce flowering unless accompanied by other treatments and in others, GAs inhibit flowering (Zeevaart, 1976; Bernier, 1988). The species in which the role of GAs as floral stimulus is best documented is Lolium temulentum (King and Evans, 2003). In this plant, a single LD is sufficient to promote flowering and this treatment induces a rapid increase of $\mathrm{GA}_{20}$ in the leaves (King and
Evans, 2003). $G A_{20}$ is a precursor of bioactive $G A s$, like $G A_{1}, G A_{5}$ and $\mathrm{GA}_{6}$ (Hedden and Phillips, 2000). A few hours later, there is a peak of $G A_{5}$ and $\mathrm{GA}_{6}$ at the shoot apex (King et al., 2001; King et al., 2003). Application of $\mathrm{GA}_{5}$ and $\mathrm{GA}_{6}$ to leaves promotes flowering in SD and LD, showing an additive effect with LD (King et al., 2001; King et al., 2003). When labelled $\mathrm{GA}_{5}$ was applied, transport to the shoot apex could be observed (King et al., 2001). These results strongly support that $\mathrm{GA}_{5}$, and perhaps $\mathrm{GA}_{6}$, might be part of the long-distance signal. However, whether the changes in GA levels at the shoot apex are the result of de novo synthesis or transport from the leaves is not known, because an increase of $\mathrm{GA}_{5}$ and $\mathrm{GA}_{6}$ in the leaves has not been documented so far. Although these results support that GAs affecting flowering can move from the leaves to the shoot apex, it is not clear to what extent these results can be extrapolated to other plant species. In fact, GAs do not seem to be a major flowering signal in $\mathcal{S}$. alba (Corbesier et al., 2004).

Endogenous GA levels also increase in Arabidopsis plants transferred from SD to LD (Xu et al., 1997). However, the GAs analysed affect stem elongation and it has not been shown whether they are involved in flowering. Furthermore, movement of these hormones might seem unnecessary because GA biosynthetic enzymes are expressed in many plant parts (Xu et al., 1997).

In potato, exogenous application of GAs has an inhibitory effect on tuberization (Fernie and Willmitzer, 2001), whereas treatment with GA biosynthesis inhibitors promotes tuber initiation (Ewing and Struik, 1992). Plants with reduced GA levels can tuberize earlier than wild-type plants in SD and LD (van den Berg et al., 1995; Carrera et al., 2000). Tuberization in SD is thought to be mediated by a decrease in GA levels, since transfer of plants from LD to SD reduces GA abundance (Jackson, 1999; Fernie and Willmitzer, 2001). Although a role for GAs in regulating tuber induction is supported by all these data, the contribution of these hormones to long-range signalling in this process has not been investigated.

Several species can be induced to flower by exogenous cytokinins, but in most cases only when the treatment is combined

TABLE 1

\section{SUMMARY OF PUTATIVE COMPONENTS OF LONG-DISTANCE FLOWERING SIGNALS}

\begin{tabular}{|c|c|c|}
\hline Compound & Supporting evidence & Evidence against \\
\hline Gibberellins & $\begin{array}{l}\text { Detected in phloem and xylem sap } \\
\text { Increase at shoot apical meristem after increase in leaves shortly after transfer } \\
\text { to inductive conditions } \\
\text { Transported from leaves to shoot apical meristem }\end{array}$ & $\begin{array}{l}\text { Opposite roles in different species } \\
\text { Not sufficient to induce flowering in several plants }\end{array}$ \\
\hline Cytokinins & Levels increase at shoot apical meristem a few hours after induction & Not sufficient to induce flowering when applied exogenously \\
\hline Sucrose & $\begin{array}{l}\text { Levels increase rapidly in leaf exudates under inductive conditions } \\
\text { Correlation between reduced sucrose levels in leaf exudates and late floral } \\
\text { induction in a starchless mutant } \\
\text { Complements the late-flowering phenotype of co mutants, affected in the } \\
\text { levels or phloem loading of the flowering signal and of a starch-deficient } \\
\text { mutant }\end{array}$ & Difficult to distinguish between signalling and metabolic effects \\
\hline Proteins and peptides & $\begin{array}{l}\text { Differences in proteins/peptides present in phloem exudates between in- } \\
\text { duced and non-induced plants }\end{array}$ & $\begin{array}{l}\text { Effect of these proteins/peptides on flowering not tested so far } \\
\text { Phloem exudates collected long after transfer to inductive conditions }\end{array}$ \\
\hline mRNAs & $\begin{array}{l}\text { Role in long-distance signalling for leaf development } \\
\text { Present in phloem sap }\end{array}$ & Effect of mobile RNAs on flowering not tested so far \\
\hline miRNAs & $\begin{array}{l}\text { Present in phloem } \\
\text { Easily exportable } \\
\text { Sequence specific } \\
\text { Affect flowering time }\end{array}$ & $\begin{array}{l}\text { Effect of miRNAs present in phloem sap on flowering not tested so far } \\
\text { Presence of miRNAs affecting flowering in the phloem not tested so far }\end{array}$ \\
\hline Salicylic acid & $\begin{array}{l}\text { Promotes flowering in Arabidopsis } \\
\text { Involved in long-distance signalling in systemic acquired resistance }\end{array}$ & $\begin{array}{l}\text { Role in long-distance signalling for flowering not tested so far } \\
\text { In systemic acquired resistance, it probably activates the synthesis of mobile } \\
\text { molecules }\end{array}$ \\
\hline
\end{tabular}


with other factors slightly inductive for flowering (Zeevaart, 1976; Bernier et al., 1993). Levels of these hormones increase in the phloem of white mustard (Sinapis alba) and Arabidopsis plants induced to flower by one LD (Lejeune et al., 1994; Corbesier et al., 2003). A few hours later, the level of specific cytokinins is higher in the shoot apical meristem of induced plants than in non-induced plants (Jacqmard et al., 2002; Corbesier et al., 2003). This extra cytokinin correlates in time with an increased flux of this hormone directed to the shoot apex in $\mathcal{S}$. alba (Lejeune et al., 1994) and with movement of the floral stimulus to the apex in Arabidopsis (Corbesier et al., 1996). Although cytokinin application to the apical bud of non-induced $S$. alba plants causes events related with the induction of flowering, such as stimulation of cell division and expression of certain genes (Bernier et al., 1993; Bonhomme et al., 2000), it is unable to promote flowering. Therefore, cytokinins are involved in the flowering process and there are changes in cytokinin fluxes at the time of floral induction in several plants, but the role of these hormones in long-distance signalling for flowering is unclear.

Although an effect of cytokinins and abscisic acid (ABA), another plant hormone, on tuber induction has been suggested, the results obtained until now are not consistent (Jackson, 1999; Fernie and Willmitzer, 2001).

\section{Sucrose}

Together with GAs, sucrose is the most extensively studied compound that might participate in long-range signalling for flowering. In $S$. alba and Arabidopsis plants exposed to inductive photoperiods, sucrose levels increase rapidly and transiently in phloem leaf exudates (Bernier etal., 1993; Corbesier etal., 1998). According to defoliation experiments (Corbesier et al., 1996), this increase coincides with the start of mobile signal transport and occurs before the activation of cell division in the meristem (Bernier et al., 1993; Corbesier et al., 1998), suggesting that sucrose could play a signalling role. Several Arabidopsis mutants affected in starch synthesis or mobilization are late-flowering in non-inductive SD, but not in inductive LD and are still sensitive to photoperiod (Corbesier et al., 1998; Yu et al., 2000). This suggests that sucrose is required for flowering in SD. In a starchless mutant, a reduction of the flowering response in inductive conditions correlates with a smaller increase in sucrose level in leaf exudates (Corbesier etal., 1998). The late flowering phenotype of another starch-deficient mutant can be rescued by addition of sucrose to the growth medium (Yu et al., 2000). Sucrose can be supplied to the aerial part of the plants by growing them on vertical plates containing sucrose. In these conditions, flowering of otherwise late-flowering Arabidopsis ecotypes is accelerated, both in LD and in darkness, indicating that sucrose affects flowering not only under SD conditions (Roldán et al., 1999). Sugar application also promotes flowering of $S$. alba, although high sucrose concentrations inhibit flowering of several species, including Arabidopsis (Bernier, 1988; Ohto et al., 2001). On vertical sucrose plates, the late-flowering phenotype of several Arabidopsis mutants is completely or almost completely corrected, whereas ft and fwa mutants flower as late as in the absence of sucrose and GA deficient and insensitive mutants flower later than the wild type (Roldán et al., 1999). Sucrose supplied to the roots also accelerates flowering of several late mutants and has no effect on $\mathrm{ft}$ and fwa (Ohto et al., 2001). These results indicate that sucrose requires GAs and the function of $F T$ and $F W A$ to promote flowering. Therefore, sucrose acts either downstream of most flowering-time genes or independently of them and either upstream of $F T$ and $F W A$ or interacting with their products. It has been reported that, in wild-type Arabidopsis plants, high sucrose can slightly delay flowering and reduce FT and SOC1 mRNA abundance, whereas in $c 0$ mutants accelerates flowering but does not increase FT and SOC1 mRNA levels (Ohto et al., 2001). Therefore, the effect of sucrose on flowering time cannot be explained through transcriptional regulation of FT and SOC1. Interestingly, the promotion of flowering by sucrose correlates with $\angle F Y$ upregulation, and treatment with GAs has a synergistic effect with sucrose on $L F Y$ expression (Blázquez et al., 1998). All these results underline the complex interactions that exist among putative components of the long-distance signals.

Sucrose strongly induces tuberization, although most observations have been done in in vitro tuberization assays and cannot be extrapolated to whole soil-grown plants (Jackson, 1999; Fernie and Willmitzer, 2001). Furthermore, tuber growth implies substantial formation of starch, making difficult a distinction between a signalling and a metabolic role for sucrose. Although the rate of tuber growth is affected in potato plants with reduced levels of the sucrose transporter SUT1, which is essential for long-distance transport of sucrose, it has not been reported whether tuberization time is also altered (Riesmeier et al., 1994; Kühn et al., 2003).

\section{Proteins and peptides}

Intercellular movement of several proteins is relevant for developmental processes, like endodermis specification in the root (Nakajima et al., 2001) and flower development (Perbal et al., 1996; Sessions et al., 2000). In these cases, cell-to-cell traffic, rather than phloem translocation of proteins, seems to be the operating mechanism. Nevertheless, polypeptides and proteins are involved in long-distance signalling in plants (Ryan et al., 2002; Lee et al., 2003).

The presence of proteins and peptides in the phloem sap of many plants has been well documented (Fisher et al., 1992; Marentes and Grusak, 1998; Haebel and Kehr, 2001; RuizMedrano et al., 2001; Hoffmann-Benning et al., 2002; Ryan et al., 2002), as well as the graft transmissibility of some of them (Golecki et al., 1999; Xoconostle-Cázares et al., 1999). More than 100 peptides and small proteins have been detected in the phloem sap of Perilla ocymoides and Lupinus albus. Four small proteins were present in phloem exudates of flowering $P$. ocymoides and absent in non-induced plants. These peptides are similar to a serine/threonine protein kinase, two purine permeases and ubiquitin and they were also detected in flowering $L$. albus (Hoffmann-Benning et al., 2002). It could be tested if any of these peptides plays a role in regulating flowering time. However, the samples used for this analysis were harvested three weeks after the beginning of the inductive treatment. Therefore, the peptides identified may be several steps downstream of the floral stimulus.

\section{Long-distance signals involved in other developmen- tal and physiological processes}

\section{Shoot development}

Alterations in the roots can lead to changes in shoot develop- 
ment and growth, suggesting that the roots send signals to the aboveground parts of the plant. Flooding of the soil induces developmental and physiological changes such as leaf epinastic curvature, decelerated leaf expansion and stomatal closure. An increased export of the immediate precursor of ethylene from the roots is likely to be part of the mobile signal that causes these modifications in the shoot. ABA has also been implicated in this signalling (Jackson, 2002).

Recent work points to a role of a carotenoid-derived substance in root to shoot communication. The bypass1 (bps 1 ) mutant of Arabidopsis produces a root-derived signal that arrests shoot development. Fluridone, which blocks carotenoid biosynthesis, partially suppressed the bps 1 phenotype, while two mutations that reduce ABA levels, aba1 and aba2, enhanced it. This suggests that the mobile signal produced by bps 1 is probably a novel carotenoid, but it is not ABA, the best characterized carotenoid-derived hormone. Since aba 1 mutants accumulate zeaxanthin, the bps 1 graft-transmissible signal could be a carotenoid derived from zeaxanthin (Van Norman et al., 2004).

The regulation of shoot branching by several plant hormones has been recently reviewed (Beveridge, 2000; Ward and Leyser, 2004). Auxin transported from the shoot apex in a basipetal direction limits branching by inhibiting axillary meristem outgrowth. Since auxin does not act directly in the bud (Ward and Leyser, 2004), it must act through mobile signals from a distance. Recent work indicates that auxin can act in the vasculature to affect axillary bud growth (Booker et al., 2003). Cytokinin has the opposite effect to auxin: it promotes branching (Ward and Leyser, 2004). Decapitation-induced branching correlates with increased concentration of cytokinins in the xylem. Application of auxin to the shoot of decapitated plants nearly eliminated the increase in cytokinins, suggesting that the induction of branching is due to a fall in auxin levels that in turn causes an elevation in cytokinins (Bangerth, 1994). The interpretation of these results is that auxin reduces cytokinin concentration in intact plants, thus limiting axillary meristem growth.

New evidence shows that cytokinin is not the only signalling molecule acting downstream of auxin. Grafting studies using pea and Arabidopsis mutants with increased branching indicate that the corresponding genes control a long-distance signal that can move from the root to the shoot (Beveridge, 2000; Ward and Leyser, 2004). These mutants do not show an increase in cytokinin or a decrease in auxin levels. Two of these genes, MORE AXILLARY BRANCHING 4 (MAX4)/RAMOSUS 1 (RMS1) and $M A X 3$, encode members of the carotenoid cleavage dioxygenase family (Sorefan et al., 2003; Booker et al., 2004) and MAX3 can cleave several carotenoids when it is expressed in $E$. coli strains that accumulate carotenoids (Booker et al., 2004). Furthermore, RMS1 expression is upregulated by auxin (Sorefan et al., 2003). These data strongly suggest that a novel graft-transmissible carotenoid-derived molecule mediates the action of auxin on shoot branching.

The implication of graft-transmissible carotenoid-derived molecules in shoot development and branching indicates that carotenoids can be part of mobile signals. Whether these molecules can be relevant for the regulation of flowering or tuberization is not known, because the long-distance signals for flowering and tuberization are transported in the phloem (Zeevaart, 1976; Jackson, 1999), whereas the signals for shoot development and branching move through the xylem (Jackson, 2002; Ward and Leyser, 2004).

\section{Leaf development}

A new perspective in long-range signalling has been opened by the study of a tomato leaf morphology mutant caused by a naturally occurring gene fusion (Kim et al., 2001). When wild-type scions were grafted onto mutant stocks, the new leaves formed in the scion showed the mutant phenotype. More importantly, the mutant mRNA was detected in the scion, indicating that a grafttransmissible mRNA is able to affect a developmental process (Kim et al., 2001). Previously, numerous mRNAs had been identified in the phloem sap of pumpkin (Cucurbita maxima) (Ruiz-Medrano et al., 1999). Altogether, this suggests that mRNAs may act as transmissible signals in other developmental processes.

\section{Systemic acquired resistance}

In response to pathogen attacks, plants produce a long-distance signal that induces disease resistance in uninfected tissues. Salicylic acid is required for the induction of this systemic acquired resistance (Durrant and Dong, 2004). Although this compound is known to move in the phloem and for some time had been considered a putative systemic signal in this process, it is more likely that regulates the synthesis of other mobile molecules (Mauch-Mani and Métraux, 1998; Durrant and Dong, 2004). Salicylic acid can induce flowering in duckweeds, although most plants do not respond to this compound (Zeevaart, 1976; Bernier et al., 1993). Very recent work shows that salicylic acid is involved in the promotion of flowering in Arabidopsis (Martínez et al., 2004). Treatment of wild-type plants with salicylic acid accelerates flowering and mutants defective in salicylic acid flower later than wildtype plants, mainly under SD conditions. The acceleration of flowering by salicylic acid is likely to be mediated at least in part by increased levels of FT mRNA (Martínez et al., 2004). This suggests that flowering and systemic acquired resistance may share mechanisms for long-distance signalling.

The production or transmission of the systemic signal for acquired resistance also requires a gene encoding a protein with homology to lipid transfer proteins (Maldonado et al., 2002). It has been proposed that this protein might help the transmissible signal to enter the vascular system or to move through the plant (Maldonado et al., 2002), suggesting that this signal might be a lipid molecule. Could FT and TFL, which are similar to lipid-binding proteins (Bradley et al., 1997; Kardailsky et al., 1999; Kobayashi et al., 1999), play an analogous role in floral signalling?

\section{Wound responses}

In wounded plants, a mechanism similar to systemic acquired resistance is triggered. Wounded leaves of tomato and potato plants release a signal that moves in the phloem to activate defence genes in distant unwounded leaves (Ryan et al., 2002). Systemin, an 18 amino acid peptide processed from a larger protein called prosystemin, analogous to polypeptide hormones in animals, is essential for long-distance signalling in this defence response (Ryan et al., 2002). FT and TFL share sequence similarity with the precursor of an eleven amino acid peptide, hippocampal cholinergic neurostimulating peptide, which affects the development of the hippocampus in animals (Tohdoh et al., 
1995). This peptide is generated by proteolytic cleavage at the amino terminal end of the precursor (Tohdoh et al., 1995). It might be worthwhile testing whether FT and TFL could be proteolytically processed in a similar way to generate peptides that might act in signal transmission.

In the wound response, systemin leads to activation of jasmonic acid synthesis (Stratmann, 2003). Recent results obtained with mutants unable to perceive systemin or jasmonic acid and mutants defective in jasmonic acid synthesis suggest that jasmonic acid could be the systemic signal (Stratmann, 2003). Jasmonic acid and a structurally related compound, called tuberonic acid, can induce tuberization in vitro (Jackson, 1999; Fernie and Willmitzer, 2001). Application of jasmonic acid to excised stolon tips from potato can induce morphological changes resembling the initial stages of tuber formation (Cenzano et al., 2003). The role of jasmonic acid in tuber induction in soil-grown plants is not clear, but it could be another candidate for the mobile signal.

\section{RNA, a new type of systemic signalling molecule}

Two types of RNA have been found in the phloem of several plant species. First, different mRNAs have been isolated from phloem sap samples of pumpkin (Ruiz-Medrano et al., 1999) and at least two of them can move across a graft junction from a pumpkin stock into a cucumber scion (Ruiz-Medrano et al., 1999; Xoconostle-Cázares et al., 1999). Furthermore, as already mentioned, a mutant mRNA affecting leaf development in tomato confers the mutant phenotype in a wild-type scion after grafting onto a mutant stock (Kim et al., 2001). Taken together, these results indicate that systemic movement of mRNA can be a mechanism for long-range signalling in plants (Lucas et al., 2001; Ding et al., 2003). This raises the possibility that mRNA could be part of the mobile signal for developmental events such as flowering and tuberization.

Second, more recently, small RNAs have been detected in the phloem sap of a variety of plants (Yoo et al., 2004). Small RNAs regulate gene expression through several mechanisms and include microRNAs (miRNAs) and short interfering RNAs (siRNAs) (Nakahara and Carthew, 2004). It has been suggested that siRNAs might participate in the systemic spread of RNA silencing, although whether these RNA molecules are the mobile silencing signal or not is a matter of debate (Mlotshwa et al., 2002). Endogenous miRNAs have been found very recently in the phloem sap of healthy pumpkin and siRNAs in the sap of viralinfected plants and spontaneously silencing transgenic plants (Yoo et al., 2004). Grafting experiments have shown that the siRNAs of spontaneously silencing transgenic stocks are grafttransmissible and can induce RNA silencing in non-silencing transgenic scions (Yoo et al., 2004), strongly suggesting that siRNAs are components of the systemic silencing signal.

Accumulation of miRNAs in Arabidopsis requires DICERLIKE1 (DCL1), a homologue of the ribonuclease responsible for processing miRNA precursors in animals (Dugas and Bartel, 2004). A mutation in DCL1 affects flowering time (Ray et al., 1996), suggesting that small RNAs might affect the induction of flowering. This has been confirmed recently by several reports showing that miRNAs are involved in flowering (Aukerman and Sakai, 2003; Palatnik et al., 2003; Achard et al., 2004; Chen, 2004). A precursor of one of these miRNAs is up-regulated after floral induction and this up-regulation requires the function of $\mathrm{CO}$ and FT (Schmid et al., 2003).

Another plant developmental process, leaf morphogenesis, is also under the influence of miRNAs (Palatnik et al., 2003; Tang et al., 2003; Juarez et al., 2004). Interestingly, a miRNA involved in specification of leaf polarity, miR166, accumulates in the phloem, suggesting that it might be a phloem-mobile signal (Juarez et al., 2004). However, since miR166 target genes are also involved in vascular patterning (McConnell and Barton, 1998; Zhong and Ye, 1999), it is unclear whether miR166 is present in the phloem to affect vascular development locally, to move to distant parts of the plant, or both.

The hypothesis that miRNAs might have a non-cell-autonomous role in the regulation of flowering time has been formulated recently (Schauer et al., 2002; Suárez-López, 2002). Small RNAs have two features that make them good candidates for the mobile signals: they carry information in their sequence, conferring them high specificity, and their small size makes them easily exportable. Furthermore, they can induce rapid turnover of mRNAs, allowing fine tuning of responses to environmental and endogenous signals, which is one of the characteristics of the floral stimulus. Testing whether any of the small RNAs or mRNAs present in phloem sap affects flowering time or tuber induction could help to elucidate a possible role of these molecules in longdistance signalling for these processes. An analysis of phloem sap for the presence of candidate mRNAs and miRNAs that regulate flowering time would also contribute to clarify this issue.

\section{Concluding remarks and perspectives}

The chemical nature of the leaf-derived signals that regulate flowering and tuberization is still uncertain. In L. temulentum, experimental results lend strong support to gibberellins, but verification that they are mobile signals has yet to be done. Many other questions are still unanswered. Are these signals universal? For GAs and other hormones, the effect on different species is dissimilar. If the composition of the signal is complex, it is possible that the same group of compounds is used by many plants but their relative contribution is different in every species, so that the limiting factor in one plant is not limiting in another. This would be a possible explanation for the lack of graft-transmissibility among certain species. On the other hand, environmental responses differ among species and the mechanisms of transport and response to the signal at target tissues could be diverse as well. Therefore, anything that can be proven for a particular species will have to be tested in many others before making any general conclusion. Nevertheless, plants with different responses can have various experimental advantages and can provide complementary information.

The isolation and detailed analysis of genes acting at different steps of the long-distance signalling should facilitate the identification of mobile molecules. In this respect, the demonstration that CONSTANS acts in the phloem and probably regulates the synthesis or phloem loading of the floral stimulus in Arabidopsis will help to elucidate the nature and mechanisms of movement of the graft-transmissible compounds. FT and TFL have several features that suggest their possible participation in the signalling mechanism, either as mobile components or as regulators of transport or sensitivity to the signal. The identification and study 
of the pea genes known to be involved in the generation or response to the floral signals would be another significant contribution to this research field.

New long-distance signalling molecules are being identified in other physiological and developmental processes. Whether they play any role in flower and tuber induction can now be examined. Several features of RNAs match to those of the transmissible signals: lability, specificity conferred by their sequence and in the case of small RNAs, reduced size that would allow their mobility. It is remarkable that a substance isolated forty years ago from flowering plants and able to promote flowering in non-induced plants had the characteristics of an organic acid (Lincoln et al., 1964). Attempts to purify this «florigenic acid» further failed (Zeevaart, 1976). Current methods would allow to test whether RNA, jasmonic acid or salicylic acid could be such compound.

Although progress in the identification of long-range flowering signals has been slow, the use of high-throughput technologies such as transcriptomics, proteomics and metabolomics, in combination with methods for isolating specific cell types can contribute to accelerate the search for these signals. It will also be essential to integrate the molecular, genetical and physiological data already available with results obtained using novel approaches.

\section{Acknowledgements}

The author thanks Ange/ Sánchez for assistance with the figure. P. S.L. was supported by a Ramón y Cajal contract from the Spanish Ministry of Science and Technology. This work was supported by grant BIO200200933 from the Spanish Ministry of Science and Technology and by the Centre de Referencia en Biotecnologia of the Generalitat de Catalunya.

\section{References}

ACHARD, P., HERR, A., BAULCOMBE, D.C. and HARBERD, N.P. (2004). Modulation of floral development by a gibberellin-regulated microRNA. Development 131: 3357-3365.

AN, H., ROUSSOT, C., SUÁREZ-LÓPEZ, P., CORBESIER, L., VINCENT, C., PIÑEIRO, M., HEPWORTH, S., MOURADOV, A., JUSTIN, S., TURNBULL, C. et al. (2004). CONSTANS acts in the phloem to regulate a systemic signal that induces photoperiodic flowering of Arabidopsis. Development 131: 3615-3626.

AUKERMAN, M.J. and SAKAI, H. (2003). Regulation of flowering time and floral organ identity by a microRNA and its APETALA2-like target genes. Plant Ce// 15:27302741.

AYRE, B.G. and TURGEON, R. (2004). Graft transmission of a floral stimulant derived from CONSTANS. Plant Physiol. 135: 2271-2278.

BANGERTH, F. (1994). Response of cytokinin concentration in the xylem exudate of bean (Phaseolus vulgaris L.) plants to decapitation and auxin treatment and relationship to apical dominance. Planta 194: 439-442.

BERNIER, G. (1988). The control of floral evocation and morphogenesis. Annu. Rev. Plant Physiol. Plant Mol. Biol. 39: 175-219.

BERNIER, G., HAVELANGE, A., HOUSSA, C., PETITJEAN, A. and LEJEUNE, P. (1993). Physiological signals that induce flowering. Plant Cell 5: 1147-1155.

BEVERIDGE, C. (2000). Long-distance signalling and a mutational analysis of branching in pea. Plant Growth Regul. 32: 193-203.

BEVERIDGE, C.A. and MURFET, I.C. (1996). The gigas mutant in pea is deficient in the floral stimulus. Physiol. Plant. 96: 637-645.

BLÁZQUEZ, M.A., GREEN, R., NILSSON, O., SUSSMAN, M.R. and WEIGEL, D. (1998). Gibberellins promote flowering of Arabidopsis by activating the $\angle E A F Y$ promoter. Plant Cel/ 10: 791-800.

BLÁZQUEZ, M.A., SOOWAL, L.N., LEE, I. and WEIGEL, D. (1997). LEAFY expression and flower initiation in Arabidopsis. Development 124: 3835-3844.

BLÁZQUEZ, M.A. and WEIGEL, D. (2000). Integration of floral inductive signals in
Arabidopsis. Nature 404: 889-892.

BONHOMME, F., KURZ, B., MELZER, S., BERNIER, G. and JACQMARD, A. (2000). Cytokinin and gibberellin activate $\operatorname{SaMADS} A$, a gene apparently involved in regulation of the floral transition in Sinapis alba. Plant J. 24: 103-111.

BOOKER, J., AULDRIDGE, M., WILLS, S., MCCARTY, D., KLEE, H. and LEYSER, O. (2004). MAX3/CCD7 is a carotenoid cleavage dioxygenase required for the synthesis of a novel plant signaling molecule. Curr. Biol. 14: 1232-1238.

BOOKER, J., CHATFIELD, S. and LEYSER, O. (2003). Auxin acts in xylemassociated or medullary cells to mediate apical dominance. Plant Cell 15: 495507.

BOSS, P.K., BASTOW, R.M., MYLNE, J.S. and DEAN, C. (2004). Multiple pathways in the decision to flower: enabling, promoting and resetting. Plant Cel/ 16 Suppl: S18-S31.

BOWMAN, J. (1994). Arabidopsis. An Atlas of Morphology and Development, New York: Springer-Verlag.

BRADLEY, D., RATCLIFFE, O., VINCENT, C., CARPENTER, R. and COEN, E. (1997). Inflorescence commitment and architecture in Arabidopsis. Science 275: 80-83.

BYRNE, M.E., KIDNER, C.A. and MARTIENSSEN, R.A. (2003). Plant stem cells: divergent pathways and common themes in shoots and roots. Curr. Opin. Genet. Dev. 13: 551-557.

CARRERA, E., BOU, J., GARCÍA-MARTÍNEZ, J.L. and PRAT, S. (2000). Changes in GA 20-oxidase gene expression strongly affect stem length, tuber induction and tuber yield of potato plants. Plant J. 22: 247-256.

CENZANO, A., VIGLIOCCO, A., KRAUS, T. and ABDALA, G. (2003). Exogenously applied jasmonic acid induces changes in apical meristem morphology of potato stolons. Ann. Bot. 91: 915-919.

CHAILAKHYAN, M.K., YANINA, L.I., DEVEDZHYAN, A.G. and LOTOVA, G.N (1981). Photoperiodism and tuber formation in grafting of tobacco onto potato. Dokl. Akad. Nauk 257: 1276-1280.

CHAPMAN, H.W. (1958). Tuberization in the potato plant. Physiol. Plant. 11:215-224.

CHEN, X. (2004). A microRNA as a translational repressor of APETALA2 in Arabidopsis flower development. Science 303: 2022-2025.

COLASANTI, J., YUAN, Z. and SUNDARESAN, V. (1998). The indeterminate gene encodes a zinc finger protein and regulates a leaf-generated signal required for the transition to flowering in maize. Cel/ 93: 593-603.

CORBESIER, L., GADISSEUR, I., SILVESTRE, G., JACQMARD, A. and BERNIER, G. (1996). Design in Arabidopsis thaliana of a synchronous system of floral induction by one long day. Plant J. 9: 947-952.

CORBESIER, L., KUSTERMANS, G., PÉRILlEUX, C., MELZER, S., MORITZ, T., HAVELANGE, A. and BERNIER, G. (2004). Gibberellins and the floral transition in Sinapis alba. Physiol. Plant. 122: 152-158.

CORBESIER, L., LEJEUNE, P. and BERNIER, G. (1998). The role of carbohydrates in the induction of flowering in Arabidopsis thaliana: comparison between the wild type and a starchless mutant. Planta 206: 131-137.

CORBESIER, L., PRINSEN, E., JACQMARD, A., LEJEUNE, P., VAN ONCKELEN, H., PÉRILLEUX, C. and BERNIER, G. (2003). Cytokinin levels in leaves, leaf exudate and shoot apical meristem of Arabidopsis thaliana during floral transition. J. Exp. Bot. 54: 2511-2517.

DING, B., ITAYA, A. and QI, Y. (2003). Symplasmic protein and RNA traffic: regulatory points and regulatory factors. Curr. Opin. Plant Biol. 6: 596-602.

DUGAS, D.V. and BARTEL, B. (2004). MicroRNA regulation of gene expression in plants. Curr. Opin. Plant Biol. 7: 512-520.

DURRANT, W.E. and DONG, X. (2004). Systemic acquired resistance. Annu. Rev. Phytopathol. 42: 185-209.

EWING, E.E. and STRUIK, P.C. (1992). Tuber formation in potato: induction, initiation and growth. Hort. Rev. 14: 89-198.

FERNIE, A.R. and WILLMITZER, L. (2001). Molecular and biochemical triggers of potato tuber development. Plant Physiol. 127: 1459-1465.

FISHER, D.B., WU, Y. and KU, M.S.B. (1992). Turnover of soluble proteins in the wheat sieve tube. Plant Physiol. 100: 1433-1441.

FOUCHER, F., MORIN, J., COURTIADE, J., CADIOUX, S., ELLIS, N., BANFIELD, M.J. and RAMEAU, C. (2003). DETERMINATE and LATE FLOWERING are two TERMINAL FLOWER1 / CENTRORADIALIS homologs that control two distinct phases of flowering initiation and development in pea. Plant Ce// 15: 2742-2754. 
GOLECKI, B., SCHULZ, A. and THOMPSON, G.A. (1999). Translocation of structural P proteins in the phloem. Plant Cel/ 11: 127-140.

GREGORY, L.E. (1956). Some factors for tuberization in the potato plant. Am. J. Bot. 43: 281-288.

HAEBEL, S. and KEHR, J. (2001). Matrix-assisted laser desorption/ionization time of flight mass spectrometry peptide mass fingerprints and post source decay: a tool for the identification and analysis of phloem proteins from Cucurbita maxima Duch. separated by two-dimensional polyacrylamide gel electrophoresis. Planta 213: 586-593.

HEDDEN, P. and PHILLIPS, A.L. (2000). Gibberellin metabolism: new insights revealed by the genes. Trends Plant Sci. 5: 523-530.

HEMPEL, F.D., WEIGEL, D., MANDEL, M.A., DITTA, G., ZAMBRYSKI, P.C., FELDMAN, L.J. and YANOFSKY, M.F. (1997). Floral determination and expression of floral regulatory genes in Arabidopsis. Development 124: 3845-3853.

HEMPEL, F.D., WELCH, D.R. and FELDMAN, L.J. (2000). Floral induction and determination: where is flowering controlled? Trends Plant Sci. 5: 17-21.

HOFFMANN-BENNING, S., GAGE, D.A., MCINTOSH, L., KENDE, H. and ZEEVAART, J.A.D. (2002). Comparison of peptides in the phloem sap of flowering and nonflowering Perilla and lupine plants using microbore HPLC followed by matrixassisted laser desorption/ionization time-of-flight mass spectrometry. Planta 216: 140-147.

JACKSON, M.B. (2002). Long-distance signalling from roots to shoots assessed: the flooding story. J. Exp. Bot. 53: 175-181.

JACKSON, S.D. (1999). Multiple signaling pathways control tuber induction in potato. Plant Physiol. 119: 1-8.

JACKSON, S.D., HEYER, A., DIETZE, J. and PRAT, S. (1996). Phytochrome B mediates the photoperiodic control of tuber formation in potato. Plant J. 9: 159166.

JACKSON, S.D., JAMES, P., PRAT, S. and THOMAS, B. (1998). Phytochrome B affects the levels of a graft-transmissible signal involved in tuberization. Plant Physiol. 117: 29-32.

JACQMARD, A., DETRY, N., DEWITTE, W., VAN ONCKELEN, H. and BERNIER, G. (2002). In situ localisation of cytokinins in the shoot apical meristem of Sinapis alba at floral transition. Planta 214: 970-973

JUAREZ, M.T., KUI, J.S., THOMAS, J., HELLER, B.A. and TIMMERMANS, M.C.P. (2004). microRNA-mediated repression of rolled leaf1 specifies maize leaf polarity. Nature $428: 84-88$.

KARDAILSKY, I., SHUKLA, V.K., AHN, J.H., DAGENAIS, N., CHRISTENSEN, S.K., NGUYEN, J.T., CHORY, J., HARRISON, M.J. and WEIGEL, D. (1999). Activation tagging of the floral inducer FT. Science 286: 1962-1965.

KIM, M., CANIO, W., KESSLER, S. and SINHA, N. (2001). Developmental changes due to long-distance movement of a homeobox fusion transcript in tomato. Science 293: 287-289.

KING, R.W. (1972). Timing in Chenopodium rubrum of export of the floral stimulus from the cotyledons and its action at the shoot apex. Can. J. Bot. 50: 697-702.

KING, R.W. and EVANS, L.T. (2003). Gibberellins and flowering of grasses and cereals: prizing open the lid of the «florigen» black box. Annu. Rev. Plant Biol. 54: 307-328.

KING, R.W., EVANS, L.T., MANDER, L.N., MORITZ, T., PHARIS, R.P. and TWITCHIN, B. (2003). Synthesis of gibberellin GA6 and its role in flowering of Lolium temulentum. Phytochemistry 62: 77-82.

KING, R.W., MORITZ, T., EVANS, L.T., JUNTTILA, O. and HERLT, A.J. (2001). Longday induction of flowering in Lolium temulentum involves sequential increases in specific gibberellins at the shoot apex. Plant Physiol. 127: 624-632.

KOBAYASHI, Y., KAYA, H., GOTO, K., IWABUCHI, M. and ARAKI, T. (1999). A pair of related genes with antagonistic roles in mediating flowering signals. Science 286: 1960-1962.

KOMEDA, Y. (2004). Genetic regulation of time to flower in Arabidopsis thaliana. Annu. Rev. Plant Biol. 55: 521-535.

KOORNNEEF, M., ALONSO-BLANCO, C., BLANKESTIJN-DE VRIES, H., HANHART, C.J. and PEETERS, A.J.M. (1998). Genetic interactions among late-flowering mutants of Arabidopsis. Genetics 148: 885-892.

KOORNNEEF, M., HANHART, C.J. and VAN DER VEEN, J.H. (1991). A genetic and physiological analysis of late flowering mutants in Arabidopsis thaliana. Mol. Gen. Genet. 229: 57-66.
KÜHN, C., HAJIREZAEI, M.-R., FERNIE, A.R., ROESSNER-TUNALI, U., CZECHOWSKI, T., HIRNER, B. and FROMMER, W.B. (2003). The sucrose transporter StSUT1 localizes to sieve elements in potato tuber phloem and influences tuber physiology and development. Plant Physiol. 131: 102-113.

KUMAR, D. and WAREING, P.F. (1973). Studies on tuberization in Solanum andigena. I. Evidence for the existence and movement of a specific tuberization stimulus. New Phytol. 72: 283-287.

LANG, A., CHAILAKHYAN, M.K. and FROLOVA, I.A. (1977). Promotion and inhibition of flower formation in a dayneutral plant in grafts with a short-day plant and a longday plant. Proc. Natl. Acad. Sci. USA 74: 2412-2416.

LEE, H., SUH, S.-S., PARK, E., CHO, E., AHN, J.H., KIM, S.-G., LEE, J.S., KWON, Y.M. and LEE, I. (2000). The AGAMOUS-LIKE 20 MADS domain protein integrates floral inductive pathways in Arabidopsis. Genes Dev. 14: 2366-2376.

LEE, J.-Y., YOO, B.-C., ROJAS, M.R., GOMEZ-OSPINA, N., STAEHELIN, L.A. and LUCAS, W.J. (2003). Selective trafficking of non-cell-autonomous proteins mediated by NtNCAPP1. Science 299: 392-396.

LEJEUNE, P., BERNIER, G., REQUIER, M.-C. and KINET, J.-M. (1994). Cytokinins in phloem and xylem saps of Sinapis alba during floral induction. Physiol. Plant. 90: 522-528.

LILJEGREN, S.J., GUSTAFSON-BROWN, C., PINYOPICH, A., DITTA, G.S. and YANOFSKY, M.F. (1999). Interactions among APETALA1, LEAFY and TERMINAL FLOWER1 specify meristem fate. Plant Cell 11: 1007-1018.

LINCOLN, R.G., CUNNINGHAM, A. and HAMNER, K.C. (1964). Evidence for a florigenic acid. Nature 202: 559-561.

LUCAS, W.J., YOO, B.-C. and KRAGLER, F. (2001). RNA as a long-distance information macromolecule in plants. Nat. Rev. Mol. Cell Biol. 2: 849-857.

MALDONADO, A.M., DOERNER, P., DIXON, R.A., LAMB, C.J. and CAMERON, R.K. (2002). A putative lipid transfer protein involved in systemic resistance signalling in Arabidopsis. Nature 419: 399-403.

MARENTES, E. and GRUSAK, M.A. (1998). Mass determination of low-molecularweight proteins in phloem sap using matrix-assisted laser desorption/ionization time-of-flight mass spectrometry. J. Exp. Bot. 49: 903-911.

MARTÍNEZ, C., PONS, E., PRATS, G. and LEÓN, J. (2004). Salicylic acid regulates flowering time and links defence responses and reproductive development. Plant J. 37: 209-217.

MARTíNEZ-GARCÍA, J.F., VIRGÓS-SOLER, A. and PRAT, S. (2002). Control of photoperiod-regulated tuberization in potato by the Arabidopsis flowering-time gene CONSTANS. Proc. Natl. Acad. Sci. USA 99: 15211-15216.

MAUCH-MANI, B. and MÉTRAUX, J.P. (1998). Salicylic acid and systemic acquired resistance to pathogen attack. Ann. Bot. 82: 535-540.

MCCONNELL, J.R. and BARTON, M.K. (1998). Leaf polarity and meristem formation in Arabidopsis. Development 125: 2935-2942.

MLOTSHWA, S., VOINNET, O., METTE, M.F., MATZKE, M., VAUCHERET, H., DING, S.W., PRUSS, G. and VANCE, V.B. (2002). RNA silencing and the mobile silencing signal. Plant Cell 14 Suppl: S289-S301.

MOURADOV, A., CREMER, F. and COUPLAND, G. (2002). Control of flowering time: interacting pathways as a basis for diversity. Plant Cel/ 14 Suppl: S111-S130.

NAKAHARA, K. and CARTHEW, R.W. (2004). Expanding roles for miRNAs and siRNAs in cell regulation. Curr. Opin. Cell Biol. 16: 127-133.

NAKAJIMA, K., SENA, G., NAWY, T. and BENFEY, P.N. (2001). Intercellular movement of the putative transcription factor SHR in root patterning. Nature 413: 307-311.

NILSSON, O., LEE, I., BLÁZQUEZ, M.A. and WEIGEL, D. (1998). Flowering-time genes modulate the response to $\angle E A F Y$ activity. Genetics 150: 403-410.

OHTO, M., ONAI, K., FURUKAWA, Y., AOKI, E., ARAKI, T. and NAKAMURA, K. (2001). Effects of sugar on vegetative development and floral transition in Arabidopsis. Plant Physiol. 127: 252-261.

OPARKA, K.J. and TURGEON, R. (1999). Sieve elements and companion cells Traffic control centers of the phloem. Plant Cell 11: 739-750.

PALATNIK, J.F., ALLEN, E., WU, X., SCHOMMER, C., SCHWAB, R., CARRINGTON, J.C. and WEIGEL, D. (2003). Control of leaf morphogenesis by microRNAs. Nature 425: 257-263.

PERBAL, M.C., HAUGHN, G., SAEDLER, H. and SCHWARZ-SOMMER, Z. (1996). Non-cell-autonomous function of the Antirrhinum floral homeotic proteins DEFICIENS and GLOBOSA is exerted by their polar cell-to-cell trafficking. 
Development 122: 3433-3441.

PÉRILLEUX, C. and BERNIER, G. (2002). The control of flowering: do genetical and physiological approaches converge? In Plant Reproduction, vol. 6 (ed. O'NEILL, S. D. and ROBERTS, J. A.). Sheffield Academic Press, Sheffield, pp.1-32.

PIDKOWICH, M.S., KLENZ, J.E. and HAUGHN, G.W. (1999). The making of a flower: control of floral meristem identity in Arabidopsis. Trends Plant Sci. 4: 64-70.

POUTEAU, S., NICHOLLS, D., TOOKE, F., COEN, E. and BATTEY, N. (1997). The induction and maintenance of flowering in Impatiens. Development 124: 33433351.

PUTTERILL, J., ROBSON, F., LEE, K., SIMON, R. and COUPLAND, G. (1995). The CONSTANS gene of Arabidopsis promotes flowering and encodes a protein showing similarities to zinc finger transcription factors. Cel/ 80: 847-857.

RATCLIFFE, O.J., AMAYA, I., VINCENT, C.A., ROTHSTEIN, S., CARPENTER, R., COEN, E.S. and BRADLEY, D.J. (1998). A common mechanism controls the life cycle and architecture of plants. Development 125: 1609-1615.

RAY, A., LANG, J.D., GOLDEN, T. and RAY, R. (1996). SHORTINTEGUMENT (SIN1 ), a gene required for ovule development in Arabidopsis, also controls flowering time. Development 1222: 2631-2638.

RIESMEIER, J.W., WILLMITZER, L. and FROMMER, W.B. (1994). Evidence for an essential role of the sucrose transporter in phloem loading and assimilate partitioning. EMBO J. 13: 1-7.

ROBSON, F., COSTA, M.M.R., HEPWORTH, S., VIZIR, I., PINEIRO, M., REEVES, P.H., PUTTERILL, J. and COUPLAND, G. (2001). Functional importance of conserved domains in the flowering-time gene CONSTANS demonstrated by analysis of mutant alleles and transgenic plants. Plant J. 28: 619-631.

ROLDÁN, M., GÓMEZ-MENA, C., RUIZ-GARCÍA, L., SALINAS, J. and MARTÍNEZZAPATER, J.M. (1999). Sucrose availability on the aerial part of the plant promotes morphogenesis and flowering of Arabidopsis in the dark. Plant J. 20: 581-590.

RUIZ-GARCÍA, L., MADUEÑO, F., WILKINSON, M., HAUGHN, G., SALINAS, J. and MARTÍNEZ-ZAPATER, J.M. (1997). Different roles of flowering-time genes in the activation of floral initiation genes in Arabidopsis. Plant Cell 9: 1921-1934.

RUIZ-MEDRANO, R., XOCONOSTLE-CÁZARES, B. and LUCAS, W.J. (1999). Phloem long-distance transport of $C m N A C P$ mRNA: implications for supracellular regulation in plants. Development 126: 4405-4419.

RUIZ-MEDRANO, R., XOCONOSTLE-CÁZARES, B. and LUCAS, W.J. (2001). The phloem as a conduit for inter-organ communication. Curr. Opin. Plant Biol. 4:202209.

RYAN, C.A., PEARCE, G., SCHEER, J. and MOURA, D.S. (2002). Polypeptide hormones. Plant Cell 14 Suppl: S251-S264.

SAMACH, A., ONOUCHI, H., GOLD, S.E., DITTA, G.S., SCHWARZ-SOMMER, Z., YANOFSKY, M.F. and COUPLAND, G. (2000). Distinct roles of CONSTANS target genes in reproductive development of Arabidopsis. Science 288: 16131616.

SCHAUER, S.E., JACOBSEN, S.E., MEINKE, D.W. and RAY, A. (2002). DICERLIKE1: blind men and elephants in Arabidopsis development. Trends Plant Sci. 7: 487-491.

SCHMID, M., UHLENHAUT, N.H., GODARD, F., DEMAR, M., BRESSAN, R., WEIGEL, D. and LOHMANN, J.U. (2003). Dissection of floral induction pathways using global expression analysis. Development 130: 6001-6012.

SEARLE, I. and COUPLAND, G. (2004). Induction of flowering by seasonal changes in photoperiod. EMBO J. 23: 1217-1222.

SESSIONS, A., YANOFSKY, M.F. and WEIGEL, D. (2000). Cell-cell signaling and movement by the floral transcription factors LEAFY and APETALA1. Science 289: 779-782.

SOREFAN, K., BOOKER, J., HAUROGNÉ, K., GOUSSOT, M., BAINBRIDGE, K., FOO, E., CHATFIELD, S., WARD, S., BEVERIDGE, C., RAMEAU, C. etal. (2003). MAX4 and RMS1 are orthologous dioxygenase-like genes that regulate shoot branching in Arabidopsis and pea. Genes Dev. 17: 1469-1474.

STRATMANN, J.W. (2003). Long distance run in the wound response - jasmonic acid is pulling ahead. Trends Plant Sci. 8: 247-250.

SUÁREZ-LÓPEZ, P. (2002). Long-distance signals that control flowering time.
Flowering Newsletter 34: 9-19.

SUÁREZ-LÓPEZ, P., WHEATLEY, K., ROBSON, F., ONOUCHI, H., VALVERDE, F. and COUPLAND, G. (2001). CONSTANS mediates between the circadian clock and the control of flowering in Arabidopsis. Nature 410: 1116-1120.

TAKADA, S. and GOTO, K. (2003). TERMINAL FLOWER2, an Arabidopsis homolog of HETEROCHROMATIN PROTEIN1, counteracts the activation of FLOWERING LOCUS $T$ by CONSTANS in the vascular tissues of leaves to regulate flowering time. Plant Cell 15: 2856-2865.

TANG, G., REINHART, B.J., BARTEL, D.P. and ZAMORE, P.D. (2003). A biochemical framework for RNA silencing in plants. Genes Dev. 17: 49-63.

TOHDOH, N., TOJO, S., AGUI, H. and OJIKA, K. (1995). Sequence homology of rat and human HCNP precursor proteins, bovine phosphatidylethanolaminebinding protein and rat $23-\mathrm{kDa}$ protein associated with the opioid-binding protein. Mol. Brain Res. 30: 381-384.

TOOKE, F., POUTEAU, S. and BATTEY, N. (1998). Non-reversion of Impatiens in the absence of meristem commitment. J. Exp. Bot. 49: 1681-1688.

TURNBULL, C. and JUSTIN, S. (2004). Graft-transmission of floral signals in Arabidopsis. Flowering Newsletter 37: 3-10.

TURNBULL, C.G.N., BOOKER, J.P. and LEYSER, H.M.O. (2002). Micrografting techniques for testing long-distance signalling in Arabidopsis. Plant J. 32: 255262.

VAN DEN BERG, J.H., SIMKO, I., DAVIES, P.J., EWING, E.E. and HALINSKA, A. (1995). Morphology and [14C]gibberellin A12 metabolism in wild-type and dwarf Solanum tuberosum ssp. andigena-grown under long and short photoperiods. J. Plant Physiol. 146: 467-473.

VAN NORMAN, J.M., FREDERICK, R.L. and SIEBURTH, L.E. (2004). BYPASS1 negatively regulates a root-derived signal that controls plant architecture. Curr. Biol. 14: 1739-1746.

WARD, S.P. and LEYSER, O. (2004). Shoot branching. Curr. Opin. Plant Biol. 7: $73-$ 78.

WASHBURN, C.F. and THOMAS, J.F. (2000). Reversion of flowering in Glycine Max (Fabaceae). Am. J. Bot. 87: 1425-1438.

WELLER, J.L., BEAUCHAMP, N., KERCKHOFFS, L.H., PLATTEN, J.D. and REID, J.B. (2001). Interaction of phytochromes $A$ and $B$ in the control of de-etiolation and flowering in pea. Plant J. 26: 283-294.

WELLER, J.L., MURFET, I.C. and REID, J.B. (1997a). Pea mutants with reduced sensitivity to far-red light define an important role for phytochrome $A$ in daylength detection. Plant Physiol. 114: 1225-1236.

WELLER, J.L., REID, J.B., TAYLOR, S.A. and MURFET, I.C. (1997b). The genetic control of flowering in pea. Trends Plant Sci. 2: 412-418.

XOCONOSTLE-CÁZARES, B., XIANG, Y., RUIZ-MEDRANO, R., WANG, H.-L., MONZER, J., YOO, B.-C., MCFARLAND, K.C., FRANCESCHI, V.R. and LUCAS, W.J. (1999). Plant paralog to viral movement protein that potentiates transport of mRNA into the phloem. Science 283: 94-98.

XU, Y.-L., GAGE, D.A. and ZEEVAART, J.A.D. (1997). Gibberellins and stem growth in Arabidopsis thaliana. Effects of photoperiod on expression of the GA4 and GA5 loci. Plant Physiol. 114: 1471-1476.

YOO, B.-C., KRAGLER, F., VARKONYI-GASIC, E., HAYWOOD, V., ARCHEREVANS, S., LEE, Y.M., LOUGH, T.J. and LUCAS, W.J. (2004). A systemic small RNA signaling system in plants. Plant Cel/ 16: 1979-2000.

YU, T.S., LUE, W.L., WANG, S.M. and CHEN, J.C. (2000). Mutation of Arabidopsis plastid phosphoglucose isomerase affects leaf starch synthesis and floral initiation. Plant Physiol. 123: 319-325.

ZAGOTTA, M.T., SHANNON, S., JACOBS, C. and MEEKS-WAGNER, D.R. (1992). Early-flowering mutants of Arabidopsis thaliana. Aust. J. Plant Physiol. 19: 411418.

ZEEVAART, J.A.D. (1976). Physiology of flower formation. Annu. Rev. Plant Physiol. 27: 321-348.

ZHONG, R.Q. and YE, Z.H. (1999). IFL1, a gene regulating interfascicular fiber differentiation in Arabidopsis, encodes a homeodomain-leucine zipper protein. Plant Cell 11: 2139-2152. 